\title{
Characterization of gene methylation in human papillomavirus associated-head and neck squamous cell carcinoma
}

\author{
H.Z. Zhang ${ }^{1}$, C.G. Shan ${ }^{1}$, A.P. Huang ${ }^{2}$ and J.M. Wang ${ }^{1}$ \\ ${ }^{1}$ Department of Otolaryngology, Head and Neck Surgery, \\ The Second Hospital of Hebei Medical University, Shijiazhuang, Hebei, China \\ ${ }^{2}$ Department of Otolaryngology, Head and Neck Surgery, \\ The Children's Hospital of Hebei, Shijiazhuang, Hebei, China \\ Corresponding author: H.Z. Zhang \\ E-mail: hz_zhang15@sina.com \\ Genet. Mol. Res. 15 (3): gmr.15038206 \\ Received December 7, 2015 \\ Accepted February 11, 2016 \\ Published August 26, 2016 \\ DOI http://dx.doi.org/10.4238/gmr.15038206 \\ Copyright (C) 2016 The Authors. This is an open-access article distributed under the terms of \\ the Creative Commons Attribution ShareAlike (CC BY-SA) 4.0 License
}

\begin{abstract}
Head and neck squamous cell carcinoma (HNSCC) has become one of the most common forms of cancer worldwide. Hypermethylation-induced silencing of tumor-associated gene has been proposed as an important cofactor in cancer pathology. This paper aimed to characterize the gene methylation patterns in human papillomavirus (HPV) associated-HNSCC. TIMP3 and APC methylation status in neoplastic $(\mathrm{N}=92)$ and non-neoplastic tissues $(\mathrm{N}$ $=92$ ) of HNSCC as well as their association with HPV infection were investigated via methylation-specific PCR assays. Results indicated that methylation level of TIMP3 was markedly higher in HPV-positive tumors as compared with HPV-negative tumors. Both TIMP3 and APC methylation were associated with lymph node metastasis and higher clinical stage of tumors. Patients with methylation at TIMP3 or APC had
\end{abstract}


worse prognoses as compared to those without these alterations. This is the first study that shows a possible linkage between HPV infection and APC methylation. Methylation patterns of tumor-related genes may contribute to different disease prognosis in HNSCC according to the HPV infection status.

Key words: TIMP3; APC; Methylation; Human papillomavirus; Head and neck squamous cell carcinoma

\section{INTRODUCTION}

Head and neck squamous cell carcinoma (HNSCC) is the 6th most common cancer worldwide with over 500,000 new diagnoses each year (Warnakulasuriya, 2009). HNSCC encompasses all squamous carcinomas that affect various head and neck regions, including the nasopharynx, oropharynx, oral cavity, hypopharynx, and larynx (Haddad and Shin, 2008). Although improvements in surgical techniques, radiation, and chemotherapeutic regimens have improved over the years, the incidence rates of HNSCC are increasing, and the overall survival rate remains at less than 50\% (Forastiere et al., 2001). Late diagnoses and frequent loco-regional recurrences are the major causes for the poor disease outcomes.

It is well accepted today that tobacco and alcohol synergistically enhance the risk of HNSCC (Blot et al., 1988; Zeka et al., 2003). In addition HPV infection has been proposed as the main factor associated with oropharyngeal squamous cell carcinoma, particularly in HPV type 16 (Miller and Johnstone, 2001; Kreimer et al., 2005). Although growing evidence demonstrates that HPV infection may serve as an important predictor of HNSCC disease prognosis and medical intervention outcomes, differences in the molecular mechanisms between HPV-negative and HPV-positive tumors have yet to be elucidated.

Epigenetic silencing down-regulates a gene through DNA methylation at $\mathrm{CpG}$ sites in the promoter region, and has been shown to participate in the development of various types of human tumors, including HNSCC (Herman and Baylin, 2003; Ha and Califano, 2006; Supić et al., 2009). Aberrant promoter methylation may affect genes involved in cell-cycle control (P16, Rb), DNA repair (MGMT and hMLH1), cell adhesion (H-cadherin and CDH1), apoptosis (DAPK), and cell differentiation (RARB2) (Miao et al., 2015; Xu et al., 2015). However, the role of gene methylation in the pathogenesis of HPV-negative and HPV-positive HNSCC remains unclear. Previous studies show that TIMP3 and APC are involved in various cellular processes, and are frequently methylated in HNSCC (Csepregi et al., 2008; Rettori et al., 2013; Xu et al., 2014). However, it is unclear whether these two genes are commonly methylated irrespective of HPV infections. In the present study, we aimed to investigate the relationship between promoter methylation and HPV infection, as well as their associated clinicopathological features.

\section{MATERIAL AND METHODS}

\section{Patients and samples}

Formalin-fixed, paraffin-embedded, and fresh frozen tissues from 92 HNSCC patients

Genetics and Molecular Research 15 (3): gmr.15038206 
were biopsied and stored at the Department of Otolaryngology, Head and Neck Surgery, the Second Hospital of Hebei Medical University, China. Patients were not given chemo- or radiotherapy prior to surgical operations. All nonmalignant specimens were freshly collected from morphologically normal tissue in the same patients. Smoking was defined as being addicted to tobacco (chewable or smoked) for at least 1 year. Alcohol use was defined as intake of more than two alcoholic drinks per day, for at least 1 year. All patients were examined via microscopy for the presence of malignant tissues. Clinical stage of cancer was determined according to the tumor-node-metastasis (TNM) criteria of the Union for International Cancer Control.

The study was approved by the Hospital Institutional Review Board, and written informed consent was given by all participants prior to participation in the study.

\section{DNA extraction and bisulfite treatment}

Genomic DNA was extracted by using the QIAamp DNeasy Blood \& Tissue Kit (Qiagen, Düsseldorf, Germany), and DNA concentration was determined with a NanoDrop 2000 spectrophotometer (Thermo Scientific, Waltham, MA, USA). Sodium bisulfite conversion of $1 \mu \mathrm{g}$ genomic DNA was performed using the EpiTect Bisulfite Kit (Qiagen) according to manufacturer instructions. The bisulfite-converted DNA was stored at $-80^{\circ} \mathrm{C}$.

\section{Quantitative methylation-specific PCR (QMSP) assay}

Following sodium bisulfite modification, QMSP assay was performed as described previously (Hou et al., 2008). In brief, $20 \mathrm{ng}$ DNA was used as the template in a final volume of $20 \mu \mathrm{L}$. The final reaction mixture contained $2 \mu \mathrm{L}$ bisulfite-modified DNA, $1.2 \mu \mathrm{M}$ forward and reverse primers, $200 \mathrm{nM}$ probe, $0.5 \mathrm{U}$ platinum Taq polymerase (Invitrogen, Carlsbad, CA, USA), $200 \mu \mathrm{M}$ dATP, dCTP, dGTP, dTTP, and $8.7 \mathrm{mM} \mathrm{MgCl}$. Sampes were ran in triplicates on 384-well plates using a 7900 Sequence detector (Applied Biosystems, Foster City, CA, USA). PCR amplifications were carried out under the following conditions: $95^{\circ} \mathrm{C}$ for $5 \mathrm{~min} ; 50$ cycles at $95^{\circ} \mathrm{C}$ for $15 \mathrm{~s}$, and $60^{\circ}-62^{\circ} \mathrm{C}$ for $1 \mathrm{~min}$. Leukocyte DNA from a healthy subject was methylated in vitro with excess SssI methyltransferase (New England Biolabs Inc., Ipswich, MA, USA) to generate completely methylated DNA. The calibration curve for the genes of interest and the reference gene was established using serial dilutions (40-0.004 ng) of this DNA and ACTB. Each plate included patient DNA samples, water blanks, and calibration curves. Primers and probes were determined to specifically amplify the promoter regions of the genes of interest and ACTB (Dahlén et al., 2004). The relative DNA methylation level of genes in each sample was analyzed as a ratio of QMSP-amplified gene to ACTB, and was then multiplied by 100 (average value of triplicates of gene of interest / average value of triplicates of ACTB x 100).

\section{Detection of HPV 16/18 DNA}

Reaction conditions, primers, and probe sequences for HPV detection have been previously described (Swan et al., 1997). PCR was performed in a total volume of $50 \mu \mathrm{L}$. PCR amplification reaction mixture contained 1X Universal Mastermix, $100 \mathrm{nM}$ probe, $200 \mathrm{nM}$ forward and reverse primers, and $150 \mathrm{ng}$ DNA. PCRs were carried out on an ABI PRISM 7700

Genetics and Molecular Research 15 (3): gmr.15038206 
Sequence Detection System (Applied Biosystems) using the following cycling parameters: $95^{\circ} \mathrm{C}$ for $10 \mathrm{~min} ; 40$ cycles of $94^{\circ} \mathrm{C}$ for $30 \mathrm{~s}, 60^{\circ} \mathrm{C}$ for $10 \mathrm{~s}$, and $65^{\circ} \mathrm{C}$ for $2 \mathrm{~min}$ (amplification for HPV 16); 40 cycles of $95^{\circ} \mathrm{C}$ for $15 \mathrm{~s}$ and $60^{\circ} \mathrm{C}$ for $1 \mathrm{~min}$ (amplification for HPV 18).

\section{Statistical analysis}

The SPSS 16.0 (IBM, Chicago, IL, USA) and Prism (GraphPad Software, San Diego, CA, USA) softwares were used for data analysis. The difference in methylation level was compared between malignant and nonmalignant samples via the paired-sample $t$-test. Thresholds of methylation genes were determined by receiver operating characteristic (ROC) analysis. A cut-off value was used to define the gene methylation status (negative or positive). The correlation between the gene methylation and clinicopathological characteristics was evaluated via the Fisher exact test. Overall survival (OS) was calculated by the Kaplan-Meier method, and differences were detected by the log-rank test. Cox proportional hazard regression analysis was applied to estimate the prognostic significance of clinical variables and individual methylation markers on overall patient survival. Hazard ratios (HRs) were calculated relative to a reference group, and was assessed by the corresponding $95 \%$ confidence interval $(95 \% \mathrm{CI})$. All tests were two-sided, with a significance level of $\mathrm{P}<0.05$.

\section{RESULTS}

\section{Patient characteristics}

Patient and tumor characteristics are summarized in Table 1 . The study included 73 males and 19 females, with ages ranging from 44 to 78 years old (mean $=62.3$ years old). Smoking and alcohol consumption in patients were found to be $64.1 \%$ (59 of 92) and $67.4 \%$ (62 of 92), respectively. Our study population also consisted of 47.8\% (44 of 92) HPV-positive patients. The majority of the patients had a tumor in either the oral cavity $(\mathrm{N}=55,59.8 \%)$ or the oropharynx $(\mathrm{N}=28,38.9 \%)$. Most patients were presented with advanced cancer stage (stage III or IV, $\mathrm{N}=52,56.5 \%)$, while the tumor in $43.5 \%(\mathrm{~N}=40)$ of the patients was in its early stage (stage I or II). Among those patients, the median follow-up period was 42.5 months (range: $5-58$ months) after surgery, with $67.4 \%$ of the patients $(\mathrm{N}=62)$ having a longer than 5 years follow-up.

\section{Methylation level of genes in HNSCC}

Gene methylation in both TIMP3 and APC was significantly increased in malignant tissues as compared to adjacent nonmalignant controls (for APC, $0.217 \pm 0.174$ in tumors $v s$ $0.151 \pm 0.025$ in controls, $\mathrm{P}<0.001$; for TIMP3, $0.633 \pm 0.336$ in tumors $v s 0.354 \pm 0.136$ in controls, $\mathrm{P}<0.001$; Figure 1A and B, paired-sample $t$-test). We also determined the degree of methylation of genes in subgroups of HNSCC cases. Results indicated that markedly higher TIMP3 methylation occurred in advanced stage tumors $(0.701 \pm 0.352$ in stage III or IV vs $0.545 \pm 0.296$ in stage I or II, $\mathrm{P}=0.023$, Mann-Whitney test; Figure $2 \mathrm{~A}$ ) as well as during lymph node metastasis $\left(0.749 \pm 0.351\right.$ in $\mathrm{N}_{1-3}$ vs $0.536 \pm 0.292$ in $\mathrm{N}_{0}, \mathrm{P}=0.001$; Figure 2B). Furthermore, methylation level of TIMP3 was significantly higher in HPV-positive tumors

Genetics and Molecular Research 15 (3): gmr.15038206 
Table 1. Frequency of methylated genes according to clinicopathological features.

\begin{tabular}{|c|c|c|c|c|c|}
\hline \multirow[t]{2}{*}{ Variables } & \multirow{2}{*}{$\begin{array}{c}\text { No. patients } \\
\mathrm{N}=92\end{array}$} & \multicolumn{2}{|c|}{ TIMP3 } & \multicolumn{2}{|c|}{ APC } \\
\hline & & \% positive & $\mathrm{P}^{\mathrm{a}}$ & \% positive & $\mathrm{P}^{\mathrm{a}}$ \\
\hline Age (years) & & & 0.897 & & 0.938 \\
\hline$<60$ & 34 & 68 & & 65 & \\
\hline$\geq 60$ & 58 & 69 & & 66 & \\
\hline Gender & & & 0.995 & & 0.052 \\
\hline Male & 73 & 69 & & 60 & \\
\hline Female & 19 & 68 & & 84 & \\
\hline Tobacco consumption & & & 0.642 & & 0.492 \\
\hline Never, Former & 29 & 66 & & 72 & \\
\hline Current & 59 & 69 & & 61 & \\
\hline Unknown & 4 & 75 & & 75 & \\
\hline Alcohol consumption & & & 0.377 & & 0.574 \\
\hline No & 26 & 62 & & 62 & \\
\hline Yes & 62 & 71 & & 66 & \\
\hline Unknown & 4 & 75 & & 75 & \\
\hline HPV $16 / 18$ status & & & 0.084 & & 0.895 \\
\hline Negative & 48 & 60 & & 65 & \\
\hline Positive & 44 & 77 & & 66 & \\
\hline Tumor site & & & 0.868 & & 0.517 \\
\hline Oral cavity & 55 & 65 & & 65 & \\
\hline Oropharynx & 28 & 79 & & 57 & \\
\hline Larynx & 9 & 56 & & 89 & \\
\hline TNM $^{\text {b }}$ stage & & & 0.003 & & 0.025 \\
\hline I, II & 40 & 53 & & 53 & \\
\hline III, IV & 52 & 81 & & 75 & \\
\hline Lymph node metastasis & & & $<0.001$ & & 0.043 \\
\hline $\mathrm{N}_{0}$ & 50 & 52 & & 56 & \\
\hline $\mathrm{N}_{1-3}$ & 42 & 81 & & 76 & \\
\hline Recurrence & & & 0.211 & & $<0.001$ \\
\hline No & 58 & 64 & & 50 & \\
\hline Yes & 34 & 76 & & 91 & \\
\hline
\end{tabular}

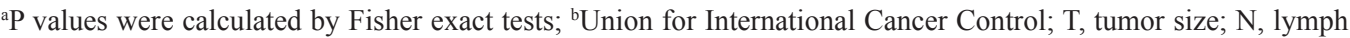
node; M, metastasis; Never, no smoking history; Former, stopped smoking for over 1 year; Current, current smoker; $P$ values $<0.05$ are presented in bold.

$(0.733 \pm 0.352)$ as comparison to HPV-negative tumors $(0.542 \pm 0.295)(\mathrm{P}=0.003$, MannWhitney test; Figure 2C). In addition, methylation level of APC was significantly higher in recurrent cases $(0.366 \pm 0.194)$ as compared to that of no recurrent cases $(0.239 \pm 0.145)(\mathrm{P}=$ 0.0001; Figure 2D).

A

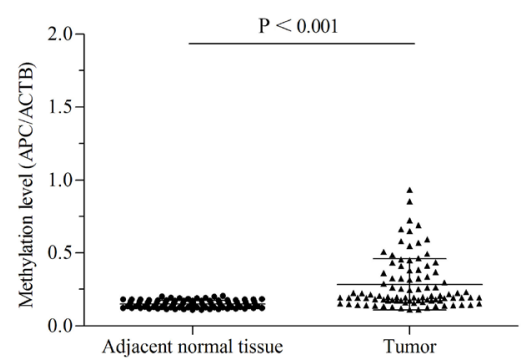

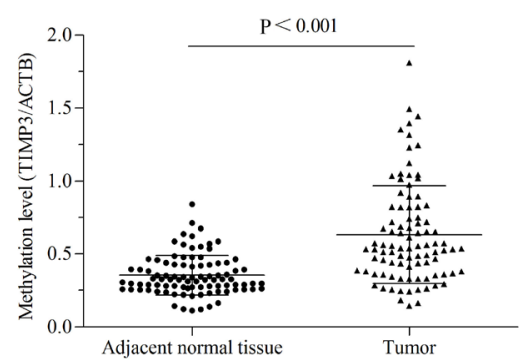

Figure 1. Methylation levels of genes between primary tumors and adjacent normal tissues. A. APC, $0.217 \pm 0.174$ in tumors $v_{s} 0.151 \pm 0.025$ in controls, $\mathrm{P}<0.001$; B. TIMP3, $0.633 \pm 0.336$ in tumors $v s 0.354 \pm 0.136$ in controls, $\mathrm{P}<0.001$. Values are reported as means $\pm \mathrm{SD}$.

Genetics and Molecular Research 15 (3): gmr.15038206 
A

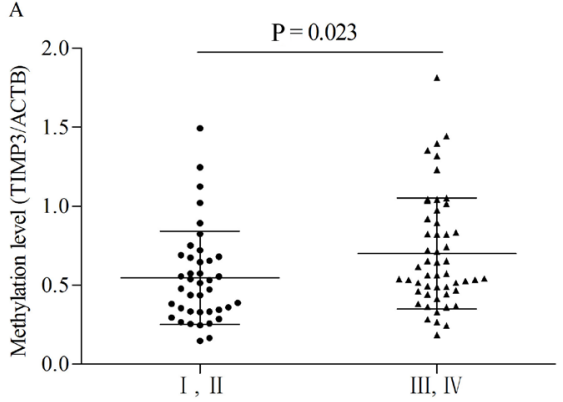

C

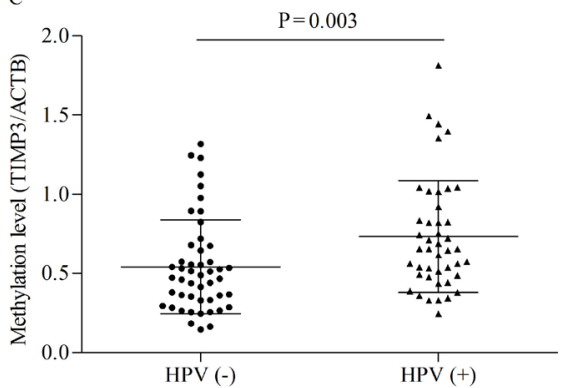

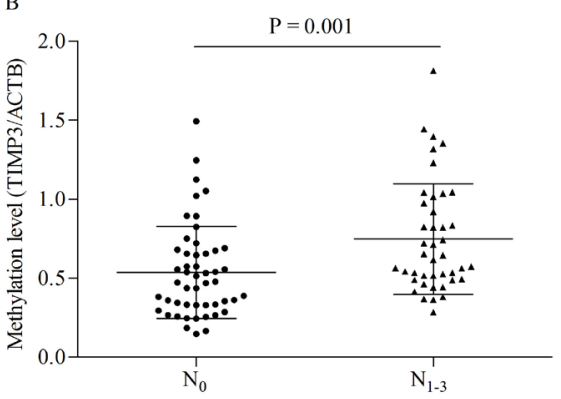

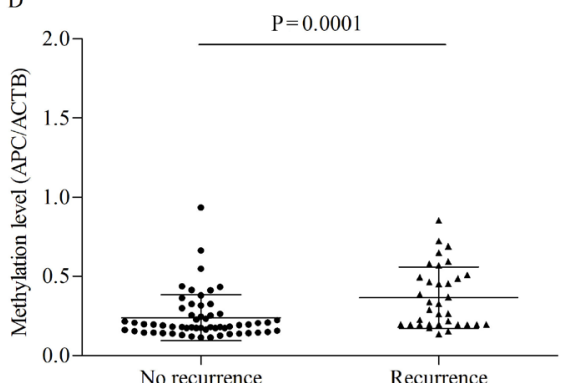

Figure 2. Methylation levels of genes in different subgroups of HNSCC cases. A. TIMP3, $0.545 \pm 0.296$ in stage I or II $v s 0.701 \pm 0.352$ in stage III or IV, $\mathrm{P}=0.023$; B. TIMP3, $0.536 \pm 0.292$ in $\mathrm{N}_{0} v s 0.749 \pm 0.351$ in $\mathrm{N}_{1-3}, \mathrm{P}=0.001$; C. TIMP3, $0.542 \pm 0.295$ in HPV-negative tumors $v s 0.733 \pm 0.352$ in HPV-positive tumors, $\mathrm{P}=0.003$; D. APC, $0.366 \pm 0.194$ in recurrent cases $v s 0.239 \pm 0.145$ in no recurrent cases, $\mathrm{P}=0.0001$.

\section{Methylation frequency and clinicopathological characteristics}

Based on ROC analysis, the frequency of TIMP3 and APC methylation in primary tumors was 68.5 and $65.2 \%$, respectively. We investigated the correlation between clinicopathological characteristics and methylation status of genes. Clinicopathological features were divided into the following categories: age ( $<60$ years $v s \geq 60$ years), HPV 16/18 (negative $v s$ positive), TNM stage (stage I or II $v s$ stage III or IV), $\mathrm{N}$ classification $\left(\mathrm{N}_{0} v s \mathrm{~N}_{1-3}\right)$, and recurrence (negative $v s$ positive).

In this study, both TIMP3 and APC were found to be more frequently methylated in advanced tumor stages as compared to early stages $(\mathrm{P}=0.003$ and $\mathrm{P}=0.025$, respectively, Fisher exact test; Table 1). Similarly, methylation of TIMP3 and APC were significantly associated with lymph node metastasis (TIMP3, P $<0.001$; APC, $\mathrm{P}=0.043$ ). In addition, methylation of APC was associated with local recurrence of tumors $(\mathrm{P}<0.001)$. Methylation frequency of TIMP3 and APC was not correlated with gender, age, tumor site, HPV 16/18 infection, tobacco, and alcohol consumption. All results are shown in Table 1.

\section{Overall survival analysis}

We analyzed the associations between clinical outcomes and methylation status of APC and TIMP3 in HNSCC patients. Our result showed that there was a significant association 
between APC and TIMP methylation in HNSCC patients and overall survival $(\mathrm{P}=0.001$, and $\mathrm{P}=0.003$, respectively, log-rank test; Figure $3 \mathrm{~A}$ and $\mathrm{B}$ ).

A

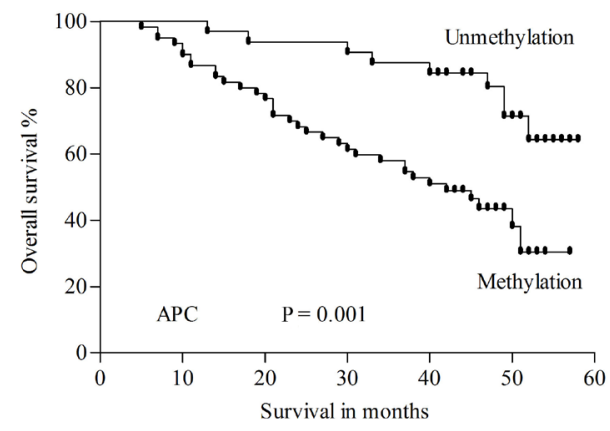

$\mathrm{B}$

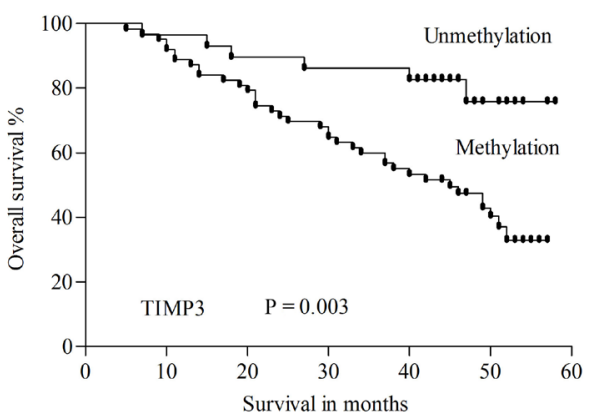

Figure 3. Overall survival of HNSCC patients with or without gene promoter methylation. A. APC, P=0.001; B. TIMP3, $\mathrm{P}=0.003$.

We then evaluated the effect of HPV 16/18 infection on disease prognosis in HNSCC patients (HPV-negative tumors vs HPV-positive tumors). Univariate analysis revealed that presence of lymph node metastasis and local tumor recurrence were significant prognostic indictors of overall survival in HPV-negative patients $(\mathrm{P}=0.002$, and $\mathrm{P}=0.027$, respectively; Table 2). Methylation of TIMP3 and APC was correlated with poor disease prognosis, with a relative risk of death of $4.18(95 \% \mathrm{CI}=1.59-11.01, \mathrm{P}=0.004)$ and $2.33(95 \% \mathrm{CI}=1.01-$ $5.37, \mathrm{P}=0.047$ ), as evaluated by HRs. The multivariate analyses included recurrence, lymph node metastasis, and methylation of APC and TIMP3. We found that TIMP3 and presence of node metastasis were independent prognostic factors that correlated with risk of death [HR values of $3.41(95 \% \mathrm{CI}=1.27-9.15, \mathrm{P}=0.015)$ and $2.65(95 \% \mathrm{CI}=1.15-6.11, \mathrm{P}=0.022)$, respectively], as shown in Table 3.

Table 2. Univariate analysis of clinicopathological variables and promoter methylation according to the Cox regression model.

\begin{tabular}{|c|c|c|c|c|c|c|}
\hline Parameter & & PV (-) tumol & & & imors & \\
\hline & HR & $95 \% \mathrm{CI}$ & P value & HR & $95 \% \mathrm{CI}$ & P value \\
\hline Age & 0.79 & $0.37-1.73$ & 0.56 & 1.44 & $0.48-4.32$ & 0.51 \\
\hline Tobacco consumption & 0.79 & $0.38-1.65$ & 0.52 & 1.36 & $0.55-3.38$ & 0.506 \\
\hline Alcohol consumption & 0.73 & $0.36-1.49$ & 0.39 & 1.45 & $0.49-4.29$ & 0.503 \\
\hline TNM Stage & 1.77 & $0.84-3.74$ & 0.13 & 4.78 & $1.07-21.45$ & 0.041 \\
\hline Lymph node metastasis & 3.41 & $1.54-7.56$ & 0.002 & 4.03 & $1.12-14.54$ & 0.033 \\
\hline Recurrence & 2.37 & $1.11-5.08$ & 0.027 & 2.37 & $0.82-6.89$ & 0.113 \\
\hline APC methylation & 2.33 & $1.01-5.37$ & 0.047 & 4.22 & $1.05-40.38$ & 0.025 \\
\hline TIMP3 methylation & 4.18 & $1.59-11.01$ & 0.004 & 4.69 & $0.61-35.9$ & 0.136 \\
\hline
\end{tabular}

$\mathrm{HR}$, hazard ratio; CI, confidence interval; $\mathrm{P}$ values $<0.05$ are presented in bold.

For overall survival analysis of HPV-positive patients, higher TNM stage (stage III or IV), lymph node metastasis $\left(\mathrm{N}_{1-3}\right)$, and APC gene methylation were significant prognostic factors. Patients with methylation on APC had an HR of $4.22(95 \% \mathrm{CI}=1.05-40.38 ; \mathrm{P}=0.025$; 
Table 2). Other clinical variables showed no prognostic significance. Moreover, methylation of the APC gene was validated to be an independent prognostic factor for poor overall survival in HPV-positive tumors based on multivariate analysis models $(\mathrm{HR}=3.25,95 \% \mathrm{CI}=1.15$ 25.10, $\mathrm{P}=0.045$, Table 3).

Table 3. Multivariate analysis.
\begin{tabular}{l|c|c|c|c|c|c}
\hline Parameters & HR & $95 \%$ CI & P value & HR & $95 \%$ CI & P value \\
\hline & 2.65 & $1.15-6.11$ & 0.022 & & & \\
\hline Lymph node metastasis & & & & 3.25 & $1.15-25.10$ & 0.045 \\
\hline APC methylation & 3.41 & $1.27-9.15$ & 0.015 & & & \\
\hline TIMP3 methylation &
\end{tabular}

HR, hazard ratio; CI, confidence interval.

\section{DISCUSSION}

HNSCC is a prevalent form of cancer, and is a major health risk worldwide. Epidemiological and laboratory studies have shown that HPV infections, particularly HPV 16 and HPV 18, serve as main instigators for the development of HNSCC. Other risk factors for HNSCC include epigenetic regulation of gene expression, which may lead to the induction and progression of HNSCC (Bragado et al., 2012; Hakami et al., 2014). Increasing evidence suggests that promoter methylation of tumor-related genes can aggravate the disease in HNSCC (Laytragoon-Lewin et al., 2013; Rettori et al., 2013; Warta et al., 2014; Shi et al., 2015). However, few studies have reported on the prognostic value of promoter methylation in HPV-induced HNSCC. The present study was conducted to investigate the prognostic significance of methylation in different HPV-induced HNSCCs.

TIMP3 is a tumor suppressor gene located on chromosome 12q12.3, and belongs to a family of genes that inhibit matrix metalloproteinase. TIMP3 has been shown to be vital in carcinogenesis of HNSCC, gastric, osteosarcoma, breast, lung, and several other types of tumors (Hou et al., 2006; De Schutter et al., 2009; Yao et al., 2012). Similar to previous findings, our result demonstrated significantly increased level of TIMP3 methylation in tumors as compared with normal tissues (Wisman et al., 2006; De Schutter et al., 2009; Yao et al., 2012; Guan et al., 2013; Rettori et al., 2013). Furthermore, we observed a correlation (P = 0.001 ) between TIMP3 promoter hypermethylation and lymph node metastasis. In addition, significantly increased methylation of TIMP3 was observed in HPV-positive tumors. These results agreed with a previous study, which also showed that higher TIMP3 methylation frequency occurs in HPV 16-positive HNSCC as compared to HPV 16-negative tumors (van Kempen et al., 2014). Several other studies proposed that HPV infection may promote hypermethylation of tumor-related genes, such as DAPK (Flatley et al., 2014), p16 (Carestiato et al., 2013), and CCNA1 (Yanatatsaneejit et al., 2011). Taken together, our data suggest that methylation of TIMP3 may be induced by HPV 16 infection.

Our study revealed that methylation frequency of APC is markedly increased in primary tumors, which was consistent with previous reports in rectal (Leong et al., 2011), breast (Mulligan et al., 2014), colorectal, and gastrointestinal cancers (Esteller et al., 2001). Furthermore, APC displayed higher degrees of methylation in patients with lymph node metastasis or higher TNM stages, which was also in accordance with results from breast cancer studies (Mulligan et al., 2014). The presence of APC methylation in primary lung or

Genetics and Molecular Research 15 (3): gmr.15038206 
colorectal tumors were indicative of worse clinical outcomes (Harden et al., 2003; Nilsson et al., 2013). We also found significant correlations between APC methylation and HNSCC prognosis. Interestingly, the methylation status of APC in hepatocellular carcinoma does not affect the overall patient survival rate (Xu et al., 2014). Tissue-specificity may explain the variations in the prognosis value of APC promoter methylation in different types of tumor.

We also investigated the effect of methylation on the clinical outcomes of HNSCC under various HPV infection statuses. As shown in Table 2, advanced disease indicated by higher $\mathrm{N}$ classification or higher TNM stage was significantly correlated with poorer outcomes. Furthermore, univariate analysis showed a strong statistical correlation between overall survival and TIMP3 methylation $(\mathrm{P}=0.004)$, which was later confirmed by multivariate analysis ( $\mathrm{P}$ $=0.015$ ). Our results suggest that TIMP3 hypermethylation may be a cofactor specifically in HPV 16/18 negative HNSCCs. In HPV-positive tumors, promoter methylation of APC, but not TIMP3, showed significant correlations with relative risk of death. Methylation of APC as an independent risk factor was also reported in lung (Usadel et al., 2002) and prostate cancers (Richiardi et al., 2013). These results suggest that methylation of tumor-related genes may contribute to different disease prognosis in HNSCC, which also depends on HPV 16/18 infection status. Of note, a larger study cohort needs to be conducted to support our present findings. This is the first study, to our knowledge, which showed a possible link between HPV 16 infection and APC methylation in HNSCC.

In conclusion, our data suggest that hypermethylation of TIMP 3 and APC is a common event in HNSCC, and is associated with poor disease prognosis. More importantly, this is the first study showing TIMP3 promoter hypermethylation as a prognostic indicator of overall disease survival in HNSCC patients without HPV infection. APC methylation analysis also appeared to be an independent prognostic factor in HPV-positive patients.

\section{Conflicts of interest}

The authors declare no conflict of interest.

\section{ACKNOWLEDGMENTS}

Research supported by the Science Foundation of Hebei Province of China (\#ZL20140084).

\section{REFERENCES}

Blot WJ, McLaughlin JK, Winn DM, Austin DF, et al. (1988). Smoking and drinking in relation to oral and pharyngeal cancer. Cancer Res. 48: 3282-3287.

Bragado P, Estrada Y, Sosa MS, Avivar-Valderas A, et al. (2012). Analysis of marker-defined HNSCC subpopulations reveals a dynamic regulation of tumor initiating properties. PLoS One 7: e29974. http://dx.doi.org/10.1371/journal. pone. 0029974

Carestiato FN, Afonso LA, Moysés N, Almeida Filho GL, et al. (2013). An upward trend in DNA p16ink4a methylation pattern and high risk HPV infection according to the severity of the cervical lesion. Rev. Inst. Med. Trop. Sao Paulo 55: 329-334. http://dx.doi.org/10.1590/S0036-46652013000500006

Csepregi A, Röcken C, Hoffmann J, Gu P, et al. (2008). APC promoter methylation and protein expression in hepatocellular carcinoma. J. Cancer Res. Clin. Oncol. 134: 579-589. http://dx.doi.org/10.1007/s00432-007-0321-y

Dahlén A, Fletcher CD, Mertens F, Fletcher JA, et al. (2004). Activation of the GLI oncogene through fusion with the

Genetics and Molecular Research 15 (3): gmr.15038206 
beta-actin gene (ACTB) in a group of distinctive pericytic neoplasms: pericytoma with $\mathrm{t}(7 ; 12)$. Am. J. Pathol. 164: 1645-1653. http://dx.doi.org/10.1016/S0002-9440(10)63723-6

De Schutter H, Geeraerts H, Verbeken E and Nuyts S (2009). Promoter methylation of TIMP3 and CDH1 predicts better outcome in head and neck squamous cell carcinoma treated by radiotherapy only. Oncol. Rep. 21: 507-513.

Esteller M, Corn PG, Baylin SB and Herman JG (2001). A gene hypermethylation profile of human cancer. Cancer Res. 61: 3225-3229.

Flatley JE, Sargent A, Kitchener HC, Russell JM, et al. (2014). Tumour suppressor gene methylation and cervical cell folate concentration are determinants of high-risk human papillomavirus persistence: a nested case control study. BMC Cancer 14: 803. http://dx.doi.org/10.1186/1471-2407-14-803

Forastiere A, Koch W, Trotti A and Sidransky D (2001). Head and neck cancer. N. Engl. J. Med. 345: 1890-1900. http:// dx.doi.org/10.1056/NEJMra001375

Guan Z, Zhang J, Song S and Dai D (2013). Promoter methylation and expression of TIMP3 gene in gastric cancer. Diagn. Pathol. 8: 110. http://dx.doi.org/10.1186/1746-1596-8-110

Ha PK and Califano JA (2006). Promoter methylation and inactivation of tumour-suppressor genes in oral squamous-cell carcinoma. Lancet Oncol. 7: 77-82. http://dx.doi.org/10.1016/S1470-2045(05)70540-4

Haddad RI and Shin DM (2008). Recent advances in head and neck cancer. N. Engl. J. Med. 359: 1143-1154. http://dx.doi. org/10.1056/NEJMra0707975

Hakami F, Darda L, Stafford P, Woll P, et al. (2014). The roles of HOXD10 in the development and progression of head and neck squamous cell carcinoma (HNSCC). Br. J. Cancer 111: 807-816. http://dx.doi.org/10.1038/bjc.2014.372

Harden SV, Tokumaru Y, Westra WH, Goodman S, et al. (2003). Gene promoter hypermethylation in tumors and lymph nodes of stage I lung cancer patients. Clin. Cancer Res. 9: 1370-1375.

Herman JG and Baylin SB (2003). Gene silencing in cancer in association with promoter hypermethylation. N. Engl. J. Med. 349: 2042-2054. http://dx.doi.org/10.1056/NEJMra023075

Hou P, Ji M, Yang B, Chen Z, et al. (2006). Quantitative analysis of promoter hypermethylation in multiple genes in osteosarcoma. Cancer 106: 1602-1609. http://dx.doi.org/10.1002/cncr.21762

Hou P, Ji M and Xing M (2008). Association of PTEN gene methylation with genetic alterations in the phosphatidylinositol 3-kinase/AKT signaling pathway in thyroid tumors. Cancer 113: 2440-2447. http://dx.doi.org/10.1002/cncr.23869

Kreimer AR, Clifford GM, Boyle P and Franceschi S (2005). Human papillomavirus types in head and neck squamous cell carcinomas worldwide: a systematic review. Cancer Epidemiol. Biomarkers Prev. 14: 467-475. http://dx.doi. org/10.1158/1055-9965.EPI-04-0551

Laytragoon-Lewin N, Rutqvist LE and Lewin F (2013). DNA methylation in tumour and normal mucosal tissue of head and neck squamous cell carcinoma (HNSCC) patients: new diagnostic approaches and treatment. Med. Oncol. 30: 654. http://dx.doi.org/10.1007/s12032-013-0654-0

Leong KJ, Wei W, Tannahill LA, Caldwell GM, et al. (2011). Methylation profiling of rectal cancer identifies novel markers of early-stage disease. Br. J. Surg. 98: 724-734. http://dx.doi.org/10.1002/bjs. 7422

Miao Z, Wu L, Lu M, Meng X, et al. (2015). Analysis of the transcriptional regulation of cancer-related genes by aberrant DNA methylation of the cis-regulation sites in the promoter region during hepatocyte carcinogenesis caused by arsenic. Oncotarget 6: 21493-21506. http://dx.doi.org/10.18632/oncotarget.4085

Miller CS and Johnstone BM (2001). Human papillomavirus as a risk factor for oral squamous cell carcinoma: a metaanalysis, 1982-1997. Oral Surg. Oral Med. Oral Pathol. Oral Radiol. Endod. 91: 622-635. http://dx.doi.org/10.1067/ moe.2001.115392

Mulligan MJ, Bernstein DI, Winokur P, Rupp R, et al.; DMID 13-0032 H7N9 Vaccine Study Group (2014). Serological responses to an avian influenza A/H7N9 vaccine mixed at the point-of-use with MF59 adjuvant: a randomized clinical trial. JAMA 312: 1409-1419. http://dx.doi.org/10.1001/jama.2014.12854

Nilsson TK, Löf-Öhlin ZM and Sun XF (2013). DNA methylation of the p14ARF, RASSF1A and APC1A genes as an independent prognostic factor in colorectal cancer patients. Int. J. Oncol. 42: 127-133.

Rettori MM, de Carvalho AC, Longo AL, de Oliveira CZ, et al. (2013). TIMP3 and CCNA1 hypermethylation in HNSCC is associated with an increased incidence of second primary tumors. J. Transl. Med. 11: 316. http://dx.doi. org/10.1186/1479-5876-11-316

Richiardi L, Fiano V, Grasso C, Zugna D, et al. (2013). Methylation of APC and GSTP1 in non-neoplastic tissue adjacent to prostate tumour and mortality from prostate cancer. PLoS One 8: e68162. http://dx.doi.org/10.1371/journal. pone. 0068162

Shi H, Chen X, Lu C, Gu C, et al. (2015). Association between P16INK4a promoter methylation and HNSCC: a metaanalysis of 21 published studies. PLoS One 10: e0122302. http://dx.doi.org/10.1371/journal.pone.0122302

Supić G, Kozomara R, Branković-Magić M, Jović N, et al. (2009). Gene hypermethylation in tumor tissue of advanced oral

Genetics and Molecular Research 15 (3): gmr.15038206 
squamous cell carcinoma patients. Oral Oncol. 45: 1051-1057. http://dx.doi.org/10.1016/j.oraloncology.2009.07.007 Swan DC, Tucker RA, Holloway BP and Icenogle JP (1997). A sensitive, type-specific, fluorogenic probe assay for detection of human papillomavirus DNA. J. Clin. Microbiol. 35: 886-891.

Usadel H, Brabender J, Danenberg KD, Jerónimo C, et al. (2002). Quantitative adenomatous polyposis coli promoter methylation analysis in tumor tissue, serum, and plasma DNA of patients with lung cancer. Cancer Res. 62: 371-375.

van Kempen PM, van Bockel L, Braunius WW, Moelans CB, et al. (2014). HPV-positive oropharyngeal squamous cell carcinoma is associated with TIMP3 and CADM1 promoter hypermethylation. Cancer Med. 3: 1185-1196. http:// dx.doi.org/10.1002/cam4.313

Warnakulasuriya S (2009). Global epidemiology of oral and oropharyngeal cancer. Oral Oncol. 45: 309-316. http://dx.doi. org/10.1016/j.oraloncology.2008.06.002

Warta R, Herold-Mende C, Chaisaingmongkol J, Popanda O, et al. (2014). Reduced promoter methylation and increased expression of CSPG4 negatively influences survival of HNSCC patients. Int. J. Cancer 135: 2727-2734. http:// dx.doi.org/10.1002/ijc.28906

Wisman GB, Nijhuis ER, Hoque MO, Reesink-Peters N, et al. (2006). Assessment of gene promoter hypermethylation for detection of cervical neoplasia. Int. J. Cancer 119: 1908-1914. http://dx.doi.org/10.1002/ijc.22060

Xu B, Nie Y, Liu X, Feng S, et al. (2014). Quantitative analysis of APC promoter methylation in hepatocellular carcinoma and its prognostic implications. Oncol. Lett. 7: 1683-1688.

Xu X, Tan X, Tampe B, Nyamsuren G, et al. (2015). Epigenetic balance of aberrant Rasal1 promoter methylation and hydroxymethylation regulates cardiac fibrosis. Cardiovasc. Res. 105: 279-291. http://dx.doi.org/10.1093/cvr/cvv015

Yanatatsaneejit P, Mutirangura A and Kitkumthorn N (2011). Human papillomavirus's physical state and cyclin A1 promoter methylation in cervical cancer. Int. J. Gynecol. Cancer 21: 902-906. http://dx.doi.org/10.1097/ IGC.0b013e3182158683

Yao D, Shi J, Shi B, Wang N, et al. (2012). Quantitative assessment of gene methylation and their impact on clinical outcome in gastric cancer. Clin. Chim. Acta 413: 787-794. http://dx.doi.org/10.1016/j.cca.2012.01.013

Zeka A, Gore R and Kriebel D (2003). Effects of alcohol and tobacco on aerodigestive cancer risks: a meta-regression analysis. Cancer Causes Control. Pap. Symp. 14: 897-906.

Genetics and Molecular Research 15 (3): gmr.15038206 